\title{
Pregnancy Outcomes at a Tertiary Care Hospital of Karnataka, South India
}

\author{
Damaru P Paneru
}

\section{ABSTRACT}

Objectives: To identify the extent of adverse pregnancy outcomes and their distributions in a tertiary care hospital of the Karnataka, South India.

Materials and methods: A retrospective study was carried out in the Department of Obstetrics and Gynecology, Dr. Prabhakar Kore Charitable Hospital of Belgaum, Karnataka, India. This is the largest multifacility referral center of the Belgaum, Karnataka. Relevant information was scrutinized from the delivery register using structured proforma. Permission was taken from hospital authority for the conduct of study. Data were analyzed using Statistical Package for the Social Sciences (SPSS) version 16.0. Percentage, mean, and standard deviation were calculated. Chi-square test and multivariate logistic regression analysis was performed. $p$-value $<0.05$ was considered significant.

Results: Totally, 1,840 pregnant women attended labor room during April to September 2012. About 4.46\% pregnancies ended at abortion and $5 \%$ delivered stillbirths (SBs). Three-fifths of the pregnancies were vaginal deliveries. Almost four-fifths were emergency cesareans among all the cesareans sections. Mean weight of the newborns was $2674 \pm 51.00 \mathrm{gm}$. Low birth weight (LBW) was observed among $27.90 \%$. Eight live births had one or other forms of congenital anomaly. Significantly, large numbers of SBs and LBW babies were born to the high-risk mothers and premature deliveries. High-risk mothers had multifold (adjusted odds ratio, 10.40) risk of delivering SBs and nearly double-fold (1.80) risk of LBW as against low-risk mothers.

Conclusion: Almost one-third pregnancies resulted in adverse outcomes. Adverse outcomes could be reduced by acting on the causes of premature births and preventing the mothers from developing risk factors through effective antenatal and intrapartum care. Further research to identify the causes of premature delivery and their preventions is recommended.

Keywords: Hospital, Pregnancy outcome, South India, Tertiary care.

How to cite this article: Paneru DP. Pregnancy Outcomes at a Tertiary Care Hospital of Karnataka, South India. J South Asian Feder Obst Gynae 2016;8(3):193-197.

Source of support: Nil

Conflict of interest: None

Date of received: 9 April 2016

Assistant Professor

School of Health and Allied Sciences, Pokhara University, Kaski Nepal

Corresponding Author: Damaru P Paneru, Assistant Professor School of Health and Allied Sciences, Pokhara University, Kaski Nepal, e-mail: damaru.paneru@gmail.com
Date of acceptance: 15 May 2016

Date of publication: July 2016

\section{INTRODUCTION}

Globally, an estimate of 210 million women become pregnant each year ${ }^{1}$; out of them, 15 to $20 \%$ results in miscarriage. ${ }^{2}$ About 2.65 million result in stillbirths (SBs), while $98 \%$ of these SBs occur in developing countries. ${ }^{3-7}$ More than $15.5 \%$ babies are born with weight $<2500 \mathrm{gm}$ wherein $96.5 \%$ of these births come from developing countries. About 15 million babies are born prematurely every year. ${ }^{1,8}$ Moreover, more than 8 million pregnant women estimated to experience life-threatening complications each year. ${ }^{1,9}$ South Asia has the highest SB rates (25 to $40 / 1,000$ births) in the world; moreover, India alone contributes to the huge burden of these adverse outcomes, i.e., an estimate of $39 \%$ of all global SBs, ${ }^{6} 40 \%$ of Asian low birth weight (LBW) babies, ${ }^{8}$ and $4.86 \%$ miscarriages ${ }^{10}$ occur annually in India.

Antepartum hemorrhage, abruption, hypertensive disorders including eclampsia, premature rapture of membrane, gestational diabetes, and many more complications have been known to precipitate adverse pregnancy outcomes. ${ }^{1-3,5,7,10}$ In the meantime, effective interventions during pregnancy and child birth can eventually reduce the adverse outcome. ${ }^{9}$ In this context, this study was carried out to identify the extent of adverse pregnancy outcomes and their distributions at a tertiary care hospital of the Karnataka, South India.

\section{MATERIALS AND METHODS}

\section{Study Design}

This was a retrospective study carried out during April to September 2012.

\section{Setting}

This study was carried out in the Department of Obstetrics and Gynecology, Dr. Prabhakar Kore Charitable Hospital of Belgaum district, Karnataka, India. This is the largest multifacility hospital of the north Karnataka, situated at the heart of Belgaum city. It has 1,300 charitable indoor beds with multiple superspecialties outpatient departments. It is the ultimate referral center of the Belgaum and adjoining districts of the Maharashtra and Karnataka. 
In addition to the routine patient care, research and academia are its harmonious jewels.

\section{Study Population and Sampling}

Records of all consecutive pregnant women who attended labor room of the study hospital during study period were studied. Abortions and twin deliveries were accounted for the descriptive findings and these were excluded for further detail analysis.

\section{Data Collection}

After taking permission from the hospital authority, maternal social and obstetric information, including the pregnancy outcomes, were scrutinized from the delivery registers using structured proforma.

\section{Data Analysis and Statistics}

The collected data were coded and entered into the spreadsheet and then analyzed using SPSS 16.0 for Windows. Percentages, means, standard deviation, odds ratio were calculated and chi-square test was applied. Multivariate logistic regression analysis was performed to observe relationship between covariates and adverse pregnancy outcomes. p-value $<0.05$ was considered significant.

\section{Definition of the Terms}

Those pregnant women coming from Municipal and cantonment boards were considered urban residents. Mother having at least one or more than one of the given (short stature $<145 \mathrm{~cm}$, bad obstetric history, hypertensive disorders, known as systemic diseases, etc.) attributes were considered high risk. Gestational age was calculated as the number of completed weeks of gestation from the 1st day of last menstruation. Expulsion of product of conception before 28 weeks of gestation irrespective of type of the termination (spontaneous or induction) was considered abortion. All those delivering before 37 weeks of gestation were considered preterm delivery. A newborn weighing < $2500 \mathrm{gm}$ was considered LBW. Intrauterine death (macerated SB) and a fetal death during the delivery (fresh $\mathrm{SB}$ ) after the period of viability was considered SB. Any inborn birth defects were considered congenital anomaly. Abortion, SBs, LBW, and presence of any congenital anomaly in new born were considered the adverse pregnancy outcomes.

\section{RESULTS}

\section{Participant Characteristics}

A total of 1,840 pregnant women attended the labor room during study period. Out of them, almost threefifths $(59.67 \%)$ were 20 to 24 years followed by a quarter between 25 and 29 years. More than half (55.27\%) were

urban residents where more than nine-tenths were Hindus. Of those whose pregnancy continued till their delivery, more than half were primi followed by second $(29.30 \%)$ gravida. More than a quarter $(28.00 \%)$ had not registered for antenatal care, nearly three-fifths were high-risk pregnancies (Table 1).

\section{Maternal Health Problems during Pregnancy}

Anemia was commonly reported among more than half (56.61\%) mothers at the time of delivery. About 1.88\% was hepatitis B positives and $2.10 \%$ had cardiovascular problems. Furthermore, among all the obstetric problems, 11.49 had hypertensive disorders and/or eclampsia followed by $6.59 \%$ reported premature rupture of membrane. Other reported problems are depicted in Table 2.

\section{Pregnancy Outcomes}

During the study period, two maternal deaths, $4.46 \%$ abortions, 30 twin deliveries and $98.30 \%$ singleton deliveries were documented. About three-fifths were vaginal deliveries. On the other hand, nearly two-fifths were cesarean sections wherein almost four out of every five were emergency cesareans. Altogether, 88 (5.00\%) were SBs; of them 75 were singleton SBs. There were $898(52.83 \%)$ male and $802(47.17 \%)$ female live births which yields a sex ratio of 893 . Nearly a quarter $(23.90 \%)$ of the singleton pregnancy delivered prematurely and $354(21.40 \%)$ were premature live births. The mean gestational age at delivery was $38.21 \pm 2.10$ weeks $(38.48 \pm$ 4.80 weeks for all singleton live births). Mean birth weight was $2674 \pm 51.00 \mathrm{gm}$ (female: $2622.79 \pm 519.74 \mathrm{gm}$;

Table 1: Participant characteristics $(n=1840)$

\begin{tabular}{|c|c|c|c|}
\hline Characteristics & $\begin{array}{l}\text { Variable } \\
\text { categories }\end{array}$ & Numbers & Percentage \\
\hline \multirow{6}{*}{$\begin{array}{l}\text { Maternal age } \\
\text { (in years) }\end{array}$} & $\leq 19$ & 130 & 7.07 \\
\hline & $20-24$ & 1098 & 59.67 \\
\hline & $25-29$ & 481 & 26.14 \\
\hline & $30-34$ & 106 & 5.76 \\
\hline & $\geq 35$ & 25 & 1.36 \\
\hline & \multicolumn{3}{|c|}{ Mean \pm standard deviation: $23.50 \pm 3.60$} \\
\hline \multirow[t]{2}{*}{ Residence } & Rural & 823 & 44.73 \\
\hline & Urban & 1017 & 55.27 \\
\hline \multirow[t]{3}{*}{ Religion } & Hindu & 1677 & 91.14 \\
\hline & Muslim & 159 & 8.64 \\
\hline & Christians & 4 & 0.22 \\
\hline \multirow[t]{3}{*}{ Gravida $(n=1758)$} & Primi & 906 & 51.50 \\
\hline & Second & 515 & 29.30 \\
\hline & Three or more & 337 & 19.20 \\
\hline \multirow{2}{*}{$\begin{array}{l}\text { ANC registration } \\
(n=1758)\end{array}$} & Unregistered & 492 & 28.00 \\
\hline & Registered & 1266 & 72.00 \\
\hline \multirow{2}{*}{$\begin{array}{l}\text { Maternal risk } \\
\text { category }(n=1758)\end{array}$} & High risk & 1002 & 57.00 \\
\hline & Low risk & 756 & 43.00 \\
\hline
\end{tabular}


Table 2: Health problems during pregnancy $(n=1758)^{*}$

\begin{tabular}{lll}
\hline Health problems & Numbers & Percentage \\
\hline A. Nonobstetric health problems & & \\
Anemia (<11 g/dL) & 995 & 56.61 \\
Cardiovascular problems & 37 & 2.10 \\
Hepatitis B & 33 & 1.88 \\
Urogenital problems & 22 & 1.25 \\
Thyroid (hypo-hyper-thyroidism) & 19 & 1.08 \\
Diabetes & 19 & 1.08 \\
Gastrointestinal problems & 18 & 1.02 \\
Miscellaneous (epilepsy, toxoplasma) & 8 & 0.45 \\
$\begin{array}{l}\text { B. Obstetric problems } \\
\text { Hypertensive disorders and/or eclampsia }\end{array}$ & 202 & 11.49 \\
Premature rupture of membrane & 116 & 6.59 \\
Antepartum hemorrhage & 27 & 1.53 \\
Miscellaneous (molar pregnancy, & 6 & 0.34 \\
genital prolapse) & & \\
*Single pregnant may have multiple nonobstetric and obstetric \\
problems
\end{tabular}

male: $2720.29 \pm 503.18 \mathrm{gm}$ ). Low birth weight was observed among $27.90 \%$ with mean birth weight of $2063.46 \pm 398.04 \mathrm{gm}$. Eight live births (4.70/1000 live births) had one or other form of congenital anomaly (Flow Chart 1).

\section{Distribution of Adverse Pregnancy Outcomes by the Covariates}

Table 3 depicts the distribution of adverse pregnancy outcomes by maternal residence, antenatal checkup (ANC) registration status, maternal risk category, new born sex, and gestational time at delivery. Significantly, higher numbers of SB and LBW babies were born to the high-risk mothers. Prematurely delivered babies had higher rates of SB and LBWs as against the full term births. Similarly, significantly more numbers of SBs were born to the unregistered mothers $(p<0.05)$. Higher proportion of LBW was observed among female new born $(<0.05)$ as against the male. Maternal residence did not make any difference on the SB and LBW. Similarly, sex of the new for SB and ANC registration status for LBW did not show any statistical relationship in this study $(\mathrm{p}>0.05)$.

Multivariate regression model depicts that the highrisk mothers and those preterm delivery / birth were independently and significantly associated with the adverse pregnancy outcomes. Similarly, unregistered mothers for ANC care and sex of the new born (female) were independent factors contributing to the SB and LBW respectively. Meanwhile, high-risk mothers had multifold (10.40) with higher risk of delivering SBs and nearly double-fold (1.80) higher risk of LBW as against low-risk mothers. Likewise, SBs and LBW babies were 8.89 and 6.38 times more likely born before full term respectively (Table 4).

\section{DISCUSSION}

Our study reported that $4.46 \%$ pregnancies ended at abortion which is lower than that was reported in Maharashtra (5.34\%) ${ }^{11}$; and India (6.50\%). ${ }^{12}$ About two-

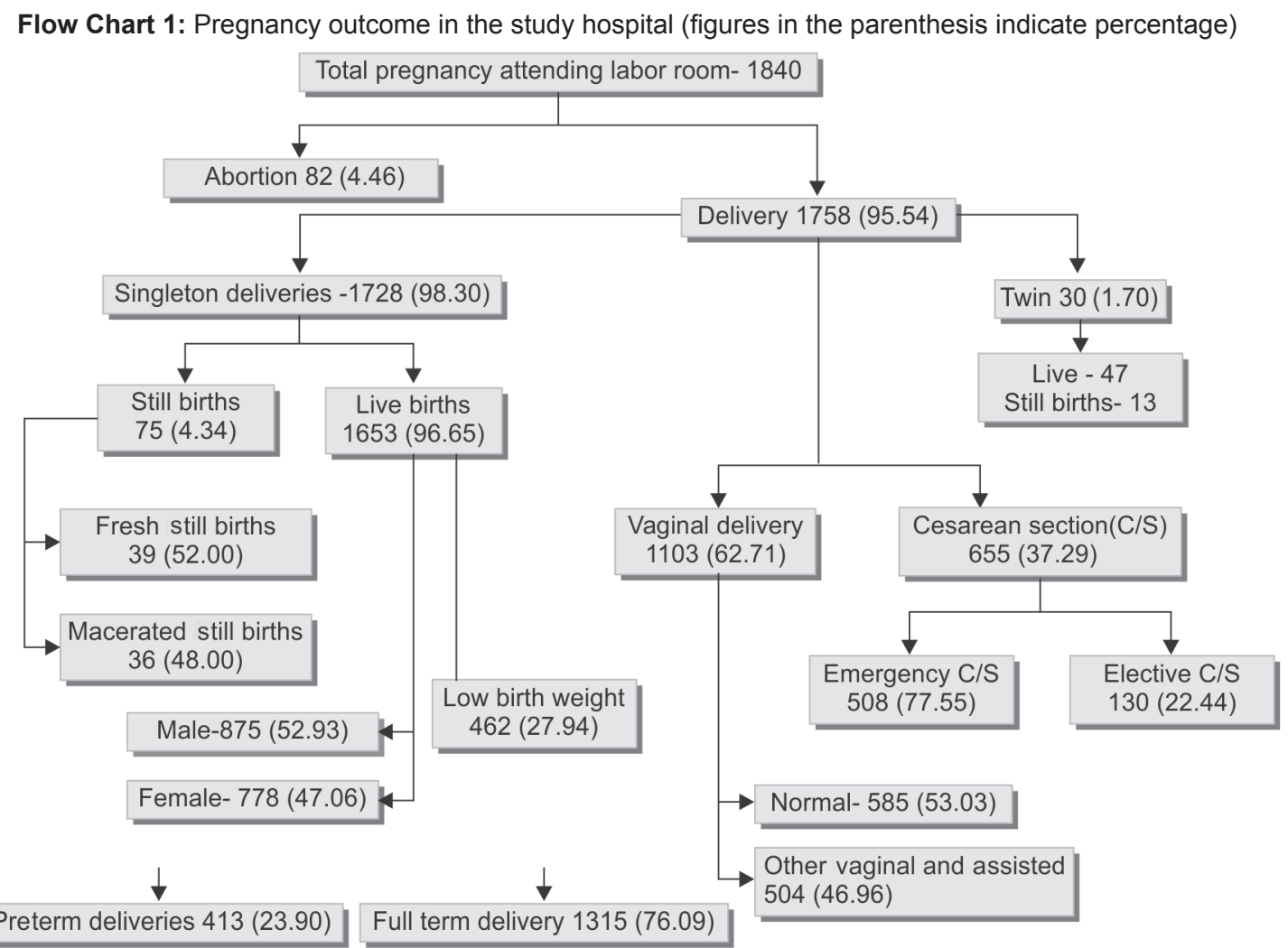


Table 3: Relationship between covariates and adverse pregnancy outcomes

\begin{tabular}{|c|c|c|c|c|c|c|}
\hline \multirow[b]{2}{*}{ Characteristics } & \multicolumn{3}{|c|}{ Still births $(n=1728)$} & \multicolumn{3}{|c|}{ LBW among live births $(n=1653)$} \\
\hline & Total & Numbers & Statistics & Total & Numbers & Statistics \\
\hline \multicolumn{7}{|l|}{ Residence } \\
\hline Rural & 773 & $31(4.00)$ & $\chi^{2}=0.36, d f-1, p>0.05$ & 742 & $219(29.50)$ & $\chi^{2}=1.63, \mathrm{df}-1, p>0.05$ \\
\hline Urban & 955 & $44(4.60)$ & & 911 & $243(26.70)$ & \\
\hline \multicolumn{7}{|l|}{ ANC registration } \\
\hline Not registered & 482 & $38(7.90)$ & $\chi^{2}=20.21, d f-1, p=0.001$ & 444 & $138(31.10)$ & $\chi^{2}=2.95, \mathrm{df}-1, p>0.05$ \\
\hline Registered & 1246 & $37(3.00)$ & & 1209 & $324(26.80)$ & \\
\hline \multicolumn{7}{|c|}{ Maternal risk category } \\
\hline High risk & 975 & $72(7.40)$ & $\chi^{2}=49.94, d f-1, p=0.001$ & 903 & $320(35.40)$ & $\chi^{2}=55.41, d f-1, p=0.001$ \\
\hline Low risk & 753 & $3(0.40)$ & & 750 & $142(18.90)$ & \\
\hline \multicolumn{7}{|l|}{ New born sex } \\
\hline Female & 811 & $33(4.10)$ & $\chi^{2}=0.27 d f-1, p>0.05$ & 778 & $240(30.80)$ & $\chi^{2}=6.13, \mathrm{df}-1, p=0.01$ \\
\hline Male & 917 & $42(4.60)$ & & 875 & $222(25.40)$ & \\
\hline \multicolumn{7}{|c|}{ Gestational age at delivery } \\
\hline Preterm & 413 & $59(14.03)$ & $\chi^{2}=129.29 \mathrm{df}-1, p=0.001$ & 354 & $211(59.60)$ & $\chi^{2}=224.15 d f-1, p=0.001$ \\
\hline Full & 1315 & $16(1.20)$ & & 1299 & $251(19.30)$ & \\
\hline
\end{tabular}

Figures in the parenthesis indicate percentage. df: Degree of freedom

Table 4: Multivariate logistic regression analysis

\begin{tabular}{|c|c|c|c|c|}
\hline \multirow[b]{2}{*}{ Variables } & \multicolumn{2}{|r|}{ Stillbirths } & \multicolumn{2}{|r|}{$\operatorname{LBW}(A O R)^{*}$} \\
\hline & $A O R$ & $p$-value, $\mathrm{Cl}$ & $A O R$ & $p$-value, $\mathrm{Cl}$ \\
\hline Unregistered vs registered & 2.20 & $p=0.002, C l=1.34-3.61$ & & - \\
\hline High risk vs low risk & 10.40 & $p=0.001, C l=3.21-33.68$ & 1.80 & $p=0.009, C l=1.41-2.30$ \\
\hline Preterm vs full term & 8.89 & $p=0.001, C l=5.01-15.83$ & 6.38 & $p=0.001, C l=497-8.20$ \\
\hline Female vs Male & - & & 1.32 & $p=0.01, C l=1.05-1.66$ \\
\hline
\end{tabular}

Reference category: Registered, low risk, full term, and male. *AOR=Adjusted odds ratio

1. Variable entered in final model: Registration, risk category, gestation age, and dependent variable: Stillbirth

2. Variable entered in final model: Registration, risk category, new born sex, gestation age, and dependent variable: Low birth weight

thirds were vaginal deliveries; almost half of them were assisted deliveries. Similar pattern of vaginal delivery was reported in Hyderabad..$^{13}$ Our study revealed that nearly two-fifths were cesarean deliveries where these findings somehow corroborates with the study of Kumari et $\mathrm{al}^{13}(36.9 \%)$ in Hyderabad; and lower than that was reported in Kolapur $(53.00 \%)^{14}$ and another study from Hyderabad (64.00\%). ${ }^{15}$ Furthermore, almost four out of every five cesarean sections were emergency sections. Similar findings were reported from Kolapur, India $(75.47 \%)$ whereas higher than that was reported in two studies from Hyderabad (59.2\%). ${ }^{14,15}$

Five percent were SBs; of them $75(88.22 \%)$ were singleton SBs. Varying proportion (1.40 to $5.97 \%$ ) of SBs were reported in India where the District Level Household Survery-3 estimated $1.40 \%$ SBs in Maharashtra and Bhattacharya et al reported (5.97\%) in West Bengal. $2,7,11,12,14,16,17$ Our findings are higher than the average of the estimates, reflecting the severity of the problem in this zone. Moreover, more than half of the SBs were fresh SBs, which corroborates with the study conducted in West Bengal (59.72\%). ${ }^{7,17}$ These indicate the urgent need for extensive quality of intrapartum care.
The sex ratio of new live born was (male:female) 1000:893, which is lower than the national and state estimates (1000:940; 1000:965) for India and Karnataka respectively and ratio is higher than that was reported in Maharashtra (850). ${ }^{11}$

Nearly a quarter of the singleton pregnancies delivered prematurely and almost one-fifths were premature live births which is lower than that was reported in one of the hospital-based study in Bareilly, India (76.5\%). ${ }^{18}$ More than a quarter $(27.90 \%)$ singleton live births were LBW. These findings are consistent to the study conducted in Kolapur in $2012^{14}$; nevertheless, the proportion of LBW was much lesser than that was reported in Lucknow and Bareilly, India. ${ }^{17,18}$ Our study reported much less proportion of new born with congenital anomaly (4.70/1000 live births) than that was identified in Wardha, India (19.10/1000 live births). ${ }^{19}$

High-risk mothers and those preterm delivery/birth were independently and significantly associated with the adverse pregnancy outcomes while those non registered mothers for ANC care and new born sex (female) are independent factors contributing to the SB and LBW respectively after controlling the confounding factors. Similar observations were done in Finland and West Bengal, 
India. ${ }^{7,19}$ Meanwhile, high-risk mothers and those who delivered prematurely had multifold higher risk of delivering SBs and LBW against low-risk mothers and full-term births. These findings are in agreement with the study done in Bareilly and Hyderabad, India. ${ }^{17,18}$

\section{CONCLUSION}

Almost one-third pregnancies resulted in adverse outcomes. High-risk pregnancies and premature deliveries were independent and significant factors contributing to both the SBs and LBW. Adverse outcomes could be reduced by acting on the causes of premature births and preventing the mothers from developing risk factors through effective antenatal and intrapartum care. Additionally, further research to identify the causes of premature delivery and their preventions is recommended.

\section{LIMITATIONS OF THE STUDY}

Despite the well-established recording system in the study hospital, a limitation of the retrospective design is also persisting in this study.

\section{ACKNOWLEDGMENTS}

Author is grateful to his research supervisor Professor Dr VA Naik and Professor (Dr) BR Nilgar for their support.

\section{REFERENCES}

1. March of Dimes, Partnership for maternal and child health, Save the children, World Health Organization. Born Too Soon: The Global Action Report on Preterm Birth. World Health Organization, 20 Avenue Appia, 1211 Geneva 27, Switzerland, 2012.

2. National Institute of Child Health and Human Development. Pregnancy loss \& miscarriage overview [Internet]. Available from: http:/ /www.nichd.nih.gov/health/topics/pregnancyloss/Pages/default.aspx\#f1.

3. Lawn JE, Blencowe H, Pattinson R, Cousens S, Kumar R, Ibiebele I, Gardosi J, Day LT, Stanton C. Stillbirths: Where? When? Why? How to make the data count. Lancet 2011 Apr;377(9775):1448-1463. Available from: www.thelancet. $\mathrm{com} / \mathrm{pdfs} /$ journals/lancet.
4. World Health Organization. Neonatal and Perinatal Mortality: Country, regional and global estimates. World Health Organization, 20 Avenue Appia, 1211 Geneva 27, Switzerland, 2006.

5. Goldenberg RL, Thompson C. The infectious origins of stillbirth. Am J Obstet Gynecol. 2003 Sep;189(3):861-873.

6. McClure EM, Nalubamba PM, Goldenberg RL. Stillbirth in developing countries. Int J Gynaecol Obstet 2006 Aug;94(2): 82-90.

7. Bhattacharya S, Mukhopadhyay G, Mistry PK, Pati S, Saha SP. Stillbirth in a tertiary care referral hospital in north Bengal - A review of causes, risk factors and prevention strategies. Online J Health Allied Sci 2010;9(4):1-4.

8. World Health Organization/United Nations Children's Fund [WHO/UNICEF]. Low Birth Weight: Country, Regional and Global Estimates. Geneva, Switzerland: WHO Publications; 2004 .

9. World Health Organization. Briefing note on achieving Millennium Development Goal (MDG) 5. Department of Reproductive Health and Research, World Health Organization, 2009. Available from: www.who.int/reproductive-health.

10. Pallikadavath SR, William SR. Miscarriage in India: a population-based study. Fertil Steril 2005 Aug;84(2):516-518.

11. Doke PP, Karantaki MV, Deshpande SR. Adverse pregnancy outcomes in rural Maharashtra, India (2008-2009): a retrospective cohort study. BMC Public Health 2012 Jul;12:543.

12. International Institute for Population Sciences (IIPS). District Level Household and Facility Survey (DLHS-3), 2007-08; India. Mumbai: IIPS; 2010.

13. Kumari PS, Thomas V. A cross sectional study of rate and determinants of caesarean sections among mothers attending government maternity hospital, Hyderabad. Int J Med Pharm Sci 2013;3(5):14-19.

14. Chaudhari DR, Shinde SM. Clinical profile and outcome of labour in cases following previous caesarean section. Int J Health Sci Res 2012;2(9):1-12.

15. Haider G, Zehra N, Munir AA, Haider A. Frequency and indications of cesarean section in a tertiary care hospital. Pak J Med Sci 2009;25(5):791-796.

16. Bang A, Reddy MH, Deshmukh MD. Child mortality in Maharashtra. Econ Polit Wkly 2002;37(49):4947-4965.

17. Idris MZ, Gupta A, Mohan U, Srivastava AK, Das V. Maternal health and low birth weight among institutional deliveries. Indian J Com Med 2000 Oct;25(4):156-160.

18. Agarwal K, Agarwal A, Agarwal VK, Agarwal P, Chaudhary V. Prevalence and determinants of low birth weight among institutional deliveries. Ann Nigerian Med 2011 Jul;5(2):48:52. Available from: www.anmjournal.com.

19. Taksande A, Vilhekar K, Chaturvedi P, Jain M. Congenital malformations at birth in central India: a rural medical college hospital based data. Ind J Hum Genet 2010 Sep;16(3):159-163. 